\title{
Turning a methanation catalyst into a methanol producer: In-Co catalysts for the direct hydrogenation of $\mathrm{CO}_{2}$ to methanol
}

\author{
A. Bavykina ${ }^{1 *}$, I. Yarulina ${ }^{1}$, L. Gevers ${ }^{1}$, M. N. Hedhili², X. Miao², A. Ramírez ${ }^{1}$, A. \\ Pustovarenko', A. Dikhtiarenko', A. Cadiau ${ }^{1}$, S. Oud-Chikh ${ }^{1}$, and J. Gascon ${ }^{1 *}$ \\ IKing Abdullah University of Science and Technology, KAUST Catalysis Center \\ (KCC), Advanced Catalytic Materials, Thuwal 23955-6900, Saudi Arabia. \\ ${ }^{2}$ King Abdullah University of Science and Technology (KAUST), Core Labs, Thuwal, \\ 23955-6900, Saudi Arabia
}

\begin{abstract}
The direct hydrogenation of $\mathrm{CO}_{2}$ to methanol using green hydrogen is regarded as a potential technology to reduce greenhouse gas emissions and the dependence on fossil fuels. For this technology to become feasible, highly selective and productive catalysts that can operate under a wide range of reaction conditions near thermodynamic conversion are required. Here, we demonstrate that indium in close contact with cobalt catalyses the formation of methanol from $\mathrm{CO}_{2}$ with high selectivity $(>80 \%)$ and productivity $\left(0.86 \mathrm{~g}_{\mathrm{CH} 3 \mathrm{OH}} \cdot \mathrm{g}_{\text {catalyst }}{ }^{-1} \cdot \mathrm{h}^{-1}\right)$ at conversion levels close to thermodynamic equilibrium, even at temperatures as high as $300{ }^{\circ} \mathrm{C}$ and at moderate pressures (50 bar). The studied In@Co system, obtained via coprecipitation, undergoes in situ transformation under the reaction conditions to form the active phase. Extensive characterization demonstrates that the active catalyst is composed of a mixed metal carbide $\left(\mathrm{Co}_{3} \mid n \mathrm{n}_{0.75}\right)$, indium oxide $\left(\mathrm{In}_{2} \mathrm{O}_{3}\right)$ and metallic $\mathrm{Co}$.
\end{abstract}

Keywords: indium, cobalt, carbon dioxide valorization, methanol synthesis

The capture and utilization of carbon dioxide, the primary greenhouse gas, are of primary importance. ${ }^{1}$ Hydrogenating $\mathrm{CO}_{2}$ into valuable feedstocks using green hydrogen offers the possibility of directly sequestering this greenhouse gas into highly demanded utility chemicals. Among the potential products, methanol is a very attractive chemical platform and clean fuel. ${ }^{2}$ Sustainable methanol production requires sources of renewable hydrogen, inexpensively captured carbon dioxide and an efficient and highly selective catalyst. ${ }^{3}$ Clean routes to produce renewable $\mathrm{H}_{2}$ by means of solar energy, hydropower, wind power or biomass are reported to be currently feasible ${ }^{4}$, while efficient carbon capture technologies require more advances. ${ }^{3}$

A few catalysts for the transformation of carbon dioxide to methanol have been documented. Photo- and electrocatalytic systems have advanced significantly over the last decades, but their performances are still rather low. ${ }^{5} \mathrm{~A}$ breakthrough in the field was recently achieved by the group of Ozin, with a report of the photothermal $\mathrm{CO}_{2}$ hydrogenation to methanol using $\ln _{2} \mathrm{O}_{3-x}(\mathrm{OH})_{y}$ with $50 \%$ selectivity and $0.06 \mathrm{mmol}$ $\mathrm{g}_{\mathrm{cat}}{ }^{-1} \mathrm{~h}^{-1}$ productivity. ${ }^{6}$ The vast majority of studies on homogeneous systems focus on indirect transformations, such as hydrogenation of formates, carbonates or urea, 
disproportionation of formic acid or cascade multi-step catalysis. ${ }^{7}$ Direct homogeneous $\mathrm{CO}_{2}$ hydrogenation is difficult to achieve, but several catalysts have been reported in recent years. ${ }^{8}$ These systems operate under relatively mild conditions $\left(125-165^{\circ} \mathrm{C}\right.$ ), but except for some prominent cases, ${ }^{9,10}$ most catalysts are based on noble metals and/or expensive phosphine ligands. ${ }^{11-14}$

Since Imperial Chemical Industries developed the first heterogeneous catalyst for methanol synthesis from a mixture of synthesis gas and $\mathrm{CO}_{2}\left(\mathrm{Cu}-\mathrm{ZnO}-\mathrm{Al}_{2} \mathrm{O}_{3}\right)$, research has focused on investigating this material. ${ }^{3}$ The ternary $\mathrm{Cu}-\mathrm{ZnO}-\mathrm{Al}_{2} \mathrm{O}_{3}$ system, however, is not perfect. The methanol selectivity at moderate pressures is limited due to the competing reverse water gas shift reaction (RWGS); moreover, stability issues arise when pure $\mathrm{CO}_{2}$ is hydrogenated. To avoid these issues, this reference catalyst is used at temperatures that do not exceed $250{ }^{\circ} \mathrm{C}$ and pressures that do not dip lower than 70 bar. Still, under these conditions, a large part of the product stream needs to be recycled to convert the produced $\mathrm{CO}$ into $\mathrm{MeOH} .{ }^{15}$ This requirement results in high compressor and cooling costs and low per-pass productivity. Catalysts that can maintain good methanol selectivity at higher temperatures and lower pressures will be cost effective and facilitate potential coupling to processes such as the methanol to olefin (MTO) process, typically operated at higher temperatures. Palladium was employed by several research groups to find a replacement for copper. Ga-promoted systems had the most success. ${ }^{16-18}$ Other metal-supported catalysts and bimetallic systems were also found to be active, such as $\mathrm{Au} / \mathrm{ZnO}\left(0.42 \mathrm{~g} \mathrm{MeOH}_{\mathrm{Au}} \mathrm{h}^{-1}\right.$, approximately $40 \%$ selectivity to produce $\mathrm{MeOH}$ under 5 bar, $240{ }^{\circ} \mathrm{C}, 15 \%$ conversion) ${ }^{19}$, Ni-Ga (approximately $0.1 \mathrm{~g}_{\mathrm{MeOH}} \mathrm{g}_{\text {catalyst }} \mathrm{h}^{-1}$ under 1 bar and $200{ }^{\circ} \mathrm{C}$, selectivity of approximately $100 \%$ ) ${ }^{20}, \mathrm{In}_{2} \mathrm{O}_{3} / \mathrm{ZrO}_{2}$ (approximately 0.3 $\mathrm{g}_{\mathrm{MeOH}} \mathrm{g}_{\text {catalyst }} \mathrm{h}^{-1}$ at 50 bar and $300{ }^{\circ} \mathrm{C}$, selectivity of approximately $100 \%, 5 \%$ conversion) ${ }^{21}$ and $\mathrm{ZnO}-\mathrm{ZrO}_{2}\left(0.73 \mathrm{gmeOH}_{\text {catalyst }} \mathrm{h}^{-1}\right.$, methanol selectivity of up to $86 \%$ with $\mathrm{CO}_{2}$ single-pass conversion of approximately $10 \%$ under 50 bar, and $320^{\circ}$ $\left.315^{\circ} \mathrm{C}\right) .^{22}$

Here we report the preparation, characterization and performance of a novel highly selective catalyst based on In and Co. The initial solid (precatalyst) is composed of $\operatorname{In}(\mathrm{OH})_{3}$ supported on $\mathrm{CO}_{3} \mathrm{O}_{4}$ prepared via co-precipitation. After a severe transformation during the first hours of reaction, the catalyst was formed and found to be mainly composed of metallic Co $(f c c)$, mixed metal carbide $\mathrm{Co}_{3} \ln \mathrm{C}_{0.75}$ and $\mathrm{In}_{2} \mathrm{O}_{3}$. Surprisingly, despite of the large amount of metallic Co, In promotion drives the selectivity towards methanol rather than towards methane formation.

\section{Results}

Multiple preparation methods were investigated for the synthesis of In@Co solids, namely, precipitation, incipient wet impregnation and ball milling (Table S1) (cf. Supplementary Information (SI)). All prepared solids showed similar trends in terms of methanol selectivity during carbon dioxide hydrogenation. However, among all the synthesized catalysts, those prepared by reverse co-precipitation provided the highest methanol productivity and the lowest $\mathrm{CH}_{4}$ selectivity (cf. Table S4). For that reason, this study focuses on the latter preparation method. A series of catalysts was prepared 
with different indium contents (see SI). The precatalyst containing $20 \mathrm{wt} \%$ of indium was found to display the best performance and is denoted as In@Co-1.

Catalytic performance. The In@Co-1 solid was tested for $\mathrm{CO}_{2}$ hydrogenation for $270 \mathrm{~h}$ at $300^{\circ} \mathrm{C}$ and $50 \mathrm{bar}$ (Figure S1). The results show an initial induction period of $30 \mathrm{~h}$ followed by a stable performance reaching a $\mathrm{CO}_{2}$ conversion of $19 \%$. The prevalent product is methanol $\left(\mathrm{S}_{\mathrm{MeOH}}=69 \%\right)$, with a limited formation of carbon monoxide $\left(\mathrm{S}_{\mathrm{CO}}=23 \%\right)$ and methane $\left(\mathrm{S}_{\mathrm{CH} 4}=8 \%\right)$ as byproducts (Figure $\left.\mathrm{S} 2\right)$. Under the same experimental conditions, the commercial $\mathrm{Cu}-\mathrm{ZnO}-\mathrm{Al}_{2} \mathrm{O}_{3}$ catalyst has no induction period but displays a much lower selectivity to methanol $\left(\mathrm{S}_{\mathrm{MeOH}}=25 \%\right)$. A comparison of the methanol productivity at the steady state $-0.45 \mathrm{vs} .0 .27 \mathrm{gmeOH}$ gcatalyst $^{-1} \mathrm{~h}^{-1}$ for In@Co-1 and Cu-ZnO- $\mathrm{Al}_{2} \mathrm{O}_{3}$, respectively - highlights an important improvement in the catalytic performance. From these results, it is clear that the activity of the Cu system in the undesired RWGS reaction is much higher than that for the Co-In system. The relatively high selectivity of In-Co towards $\mathrm{CH}_{4}$ suggests that part of the catalyst contains accessible Co nanoparticles, which are well known for their high methanation activity.

Structural rearrangement during the catalytic test. The observation of a long induction period is usually a clear indication that the active catalytic phase forms under the reaction conditions. Furthermore, we noticed a strong pyrophoric behaviour of the final In@Co-1 catalyst. Hence, the structural characterization of the spent catalyst was conducted with appropriate precautions to avoid any air exposure (details in the $\mathrm{SI}$ ). In the following section, the structural rearrangements subsequent to $\mathrm{CO}_{2}$ hydrogenation are presented in detail.

The reverse co-precipitation with a metal solution including both $\ln \left(\mathrm{CH}_{3} \mathrm{CO}_{2}\right)_{3}$ and $\mathrm{Co}\left(\mathrm{CH}_{3} \mathrm{CO}_{2}\right)_{2}$ salts and an ammonia solution as a precipitation agent, followed by hydrothermal treatment, initially produces a mixture of dzhalindite $\left(\ln (\mathrm{OH})_{3}\right)$ and cobalt (II, III) oxide $\left(\mathrm{Co}_{3} \mathrm{O}_{4}\right)$ as nanoparticles. This result is easily identified in Figure 1 by considering the ensemble of $d$-spacings observed by powder X-ray diffraction (PXRD). The precipitation is nearly quantitative, with a synthesis yield of $61 \%$ based on indium and $59 \%$ based on cobalt. 


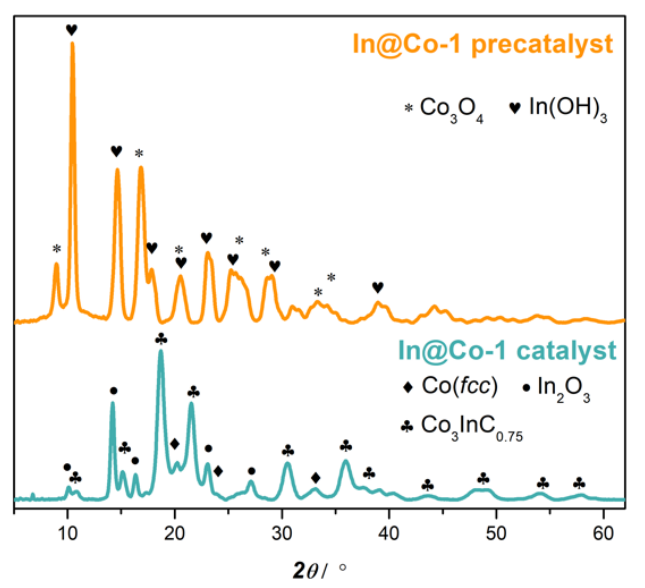

Figure 1. Powder XRD patterns of the In@Co-1 solid before and after reaction acquired in transmission with flame-sealed capillaries and using Mo Ka radiation as the $\mathrm{X}$-ray source. The assignment of the main reflections is labelled as follows: $* \mathrm{Co}_{3} \mathrm{O}_{4}, \bullet \operatorname{In}(\mathrm{OH})_{3}, * \mathrm{Co}_{3} \operatorname{InC} \mathrm{C}_{0.75}, \mathrm{Co}(\mathrm{fcc}), \bullet \mathrm{In}_{2} \mathrm{O}_{3}$.

The nitrogen adsorption-desorption isotherm of the In@Co-1 precatalyst (Figure S3a) is between a type II and IV isotherm according to the IUPAC classification. This type of isotherm is characteristic of mesoporous/macroporous solids. In@Co-1, the precatalyst, has a low specific surface area of $30 \mathrm{~m}^{2} \mathrm{~g}^{-1}$.

Imaging by annular dark field scanning transmission electron microscopy (ADFSTEM) was used to investigate the morphological properties of the In@Co-1 catalyst before reaction. The micrograph presented in Figure S4 shows a typical example of agglomerates containing round $\mathrm{CO}_{3} \mathrm{O}_{4}$ nanoparticles in the 10-40 nm range and larger $\ln (\mathrm{OH})_{3}$ nanoparticles shaped as rectangular parallelepipeds (> $100 \mathrm{~nm} \times 50 \mathrm{~nm}$ ). Furthermore, Co and In elemental maps computed from electron energy loss spectroscopy (EELS) reveal that some of the $\mathrm{Co}_{3} \mathrm{O}_{4}$ aggregates are sometimes filled or trapped within an amorphous indium hydroxide phase (Figure S4, c and d).

The high-resolution X-ray photoelectron spectroscopy (XPS) image of the Co $2 p$ core level of the sample before reaction is shown in Figure $2 a$ (top). The spectrum consists of two main broad peaks at $779.8 \mathrm{eV}$ and $794.9 \mathrm{eV}$ corresponding to $2 \mathrm{p}_{3 / 2}$, $2 p_{1 / 2}$ spin orbit lines, respectively. The spectrum also contains satellite structures at the high binding energy side of the $2 p_{3 / 2}$ and $2 p_{1 / 2}$ main peaks, which indicates the existence of cobalt in oxide form. ${ }^{24,25}$ To identify the oxidation state of cobalt, peak fitting of Co $2 p_{3 / 2}$ was conducted. The approach used for the peak fitting is similar to that used by Biesinger et al. ${ }^{26}$, i.e., fitting of a broad main peak combined with the satellite structure. A Shirley background was applied across the Co $2 p_{3 / 2}$ peak of the spectrum. The Co $2 p_{3 / 2}$ from the sample before reaction in Figure 2 is well fitted using a combination of the parameters derived from both $\mathrm{Co}_{3} \mathrm{O}_{4}$ and $\mathrm{Co}(\mathrm{OH})_{2}$ standard samples. The results indicate that the sample contains $82.5 \%$ of $\mathrm{Co}_{3} \mathrm{O}_{4}$ and the remaining $17.5 \%$ of the extra $\mathrm{Co}(\mathrm{OH})_{2}$ contribution. Since $\mathrm{Co}(\mathrm{OH})_{2}$ was not detected by XRD, we propose that this could be related to the presence of an amorphous Co hydroxide. The high-resolution XPS spectrum of the In $3 \mathrm{~d}$ core level (Figure $2 \mathrm{~b}$, top) consists of two main broad peaks at $445.0 \mathrm{eV}$ and $452.6 \mathrm{eV}$ corresponding to $3 \mathrm{~d}_{5 / 2}$, 
$3 d_{3 / 2}$ spin orbit lines, respectively. The In $3 d_{5 / 2}$ peak was fitted using a single component located at $445.0 \mathrm{eV}$ attributed to $\ln ^{3+}$ in $\ln (\mathrm{OH})_{3}{ }^{27}$ Figure $2 \mathrm{C}$ (top) shows the high-resolution XPS spectrum of the $C 1$ s core level of the sample. The $C 1 \mathrm{~s}$ core level from the sample before reaction was fitted using four components located at $285.0 \mathrm{eV}$, $286.4 \mathrm{eV}, 288.3 \mathrm{eV}$ and $289.5 \mathrm{eV}$ corresponding to the $\mathrm{C}-\mathrm{C} / \mathrm{C}-\mathrm{H}$ (sp3), C-O, C=O and $\mathrm{O}-\mathrm{C}=\mathrm{O}$ bonds, ${ }^{28,29}$ respectively. These contributions indicate that acetate anions remain adsorbed on the surface of the In@Co solid despite extensive washing.

a) Co $2 p$

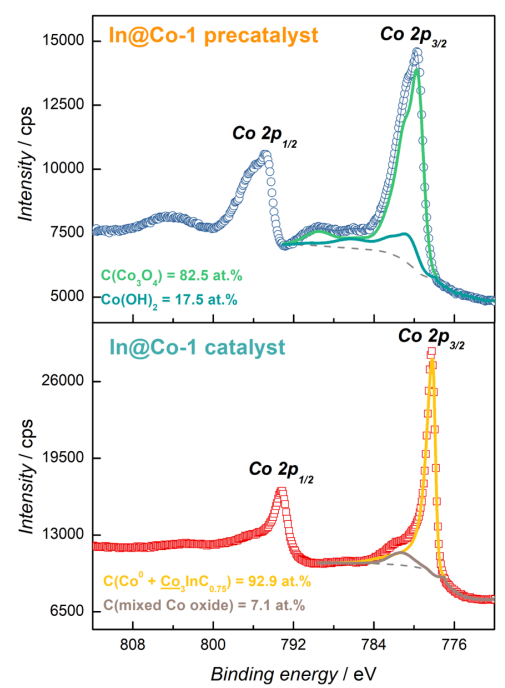

b) In 3d

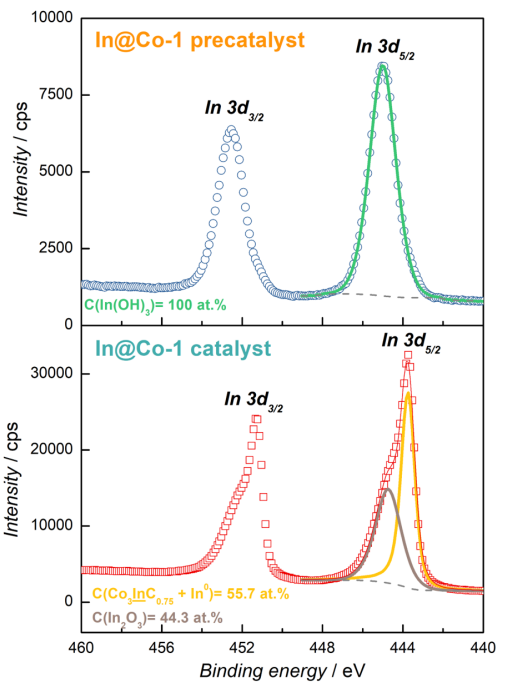

c) $\mathrm{C} 1 \mathrm{~s}$

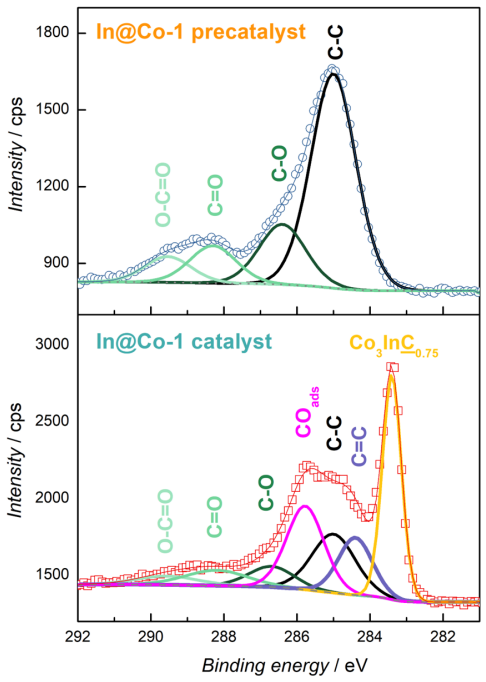

Figure 2 High-resolution X-ray photoelectron spectroscopy study of the In@Co-1 solid before and after reaction with core levels a) Co(2p), b) In(3d), and c) C(1s). The open symbols are the experimental data, while the full lines are the components used for the decomposition of the spectra.

After $\mathrm{CO}_{2}$ hydrogenation, large changes in the phase composition and morphological properties are observed, although the textural properties remain comparable $\left(S_{B E T}\right.$ (precatalyst) $=30 \mathrm{~m}^{2} / \mathrm{g}$ vs. $S_{B E T}$ (catalyst) $\left.=17 \mathrm{~m}^{2} / \mathrm{g}\right)$. All of the indium hydroxide converts into indium oxide $\left(\ln _{2} \mathrm{O}_{3}\right)$ by dehydration (Figure 1). The thermal decomposition likely occurs during preheating under $\mathrm{N}_{2}$ at $300{ }^{\circ} \mathrm{C}$ because this transformation is known to occur at approximately $220{ }^{\circ} \mathrm{C} .{ }^{30}$ Additionally, the cobalt oxide transforms into metallic Co that crystallizes in a face-centred cubic crystal system. However, the most striking evolution is the appearance of a mixed metal carbide with the $\mathrm{Co}_{3} \ln \mathrm{C}_{0.75}$ stoichiometry as the major crystalline phase in the spent catalyst. Note also that none of the reported Co-In intermetallic compounds (Coln $2^{31}$, $\mathrm{Coln}_{3}{ }^{32}$ ) or pure metallic indium was detected.

The fate of each phase in the precatalyst was also characterized after $\mathrm{CO}_{2}$ hydrogenation using ADF-STEM imaging and EELS (Figure 3). The large and rectangular $\ln (\mathrm{OH})_{3}$ nanoparticles are converted into much smaller $\ln _{2} \mathrm{O}_{3}$ crystallites (Figure $\mathrm{S} 5 \mathrm{a}, \mathrm{b}$ and purple colour in Figure $3 \mathrm{~b}$ ). The $\mathrm{Co}_{3} \mathrm{O}_{4}$ nanoparticles are transformed into metallic Co nanoparticles (Figure $\mathrm{S} 5 \mathrm{c}, \mathrm{d}$ and green colour in Figure $3 \mathrm{~b}$ ). The previous aggregates of $\mathrm{Co}_{3} \mathrm{O}_{4}$ nanoparticles, which were in contact with amorphous indium hydroxide, are likely the starting precursor for the formation of $\mathrm{Co}_{3} \ln \mathrm{C}_{0.75}$ carbide (cyan colour in Figure 3b). Interestingly, there is also a new component in the 
spent catalyst that is often observed but cannot be detected by XRD. This is illustrated in Figure 3 using ADF imaging at high magnification (Figure 3a), where some metallic Co nanoparticles are decorated with a lighter material. Quantitative analysis of the EELS data (details in the SI) indicates that the presence of the lighter material is due to the formation of an oxidized indium-cobalt layer with a range of thicknesses between 1 and $4 \mathrm{~nm}$ (Figure $3 \mathrm{~b}$ ). This surface layer includes an irregular amount of oxygen through the sample and still contains much more cobalt than indium atoms (minimum Co/ln ratio measured $\approx 2.5$ ).

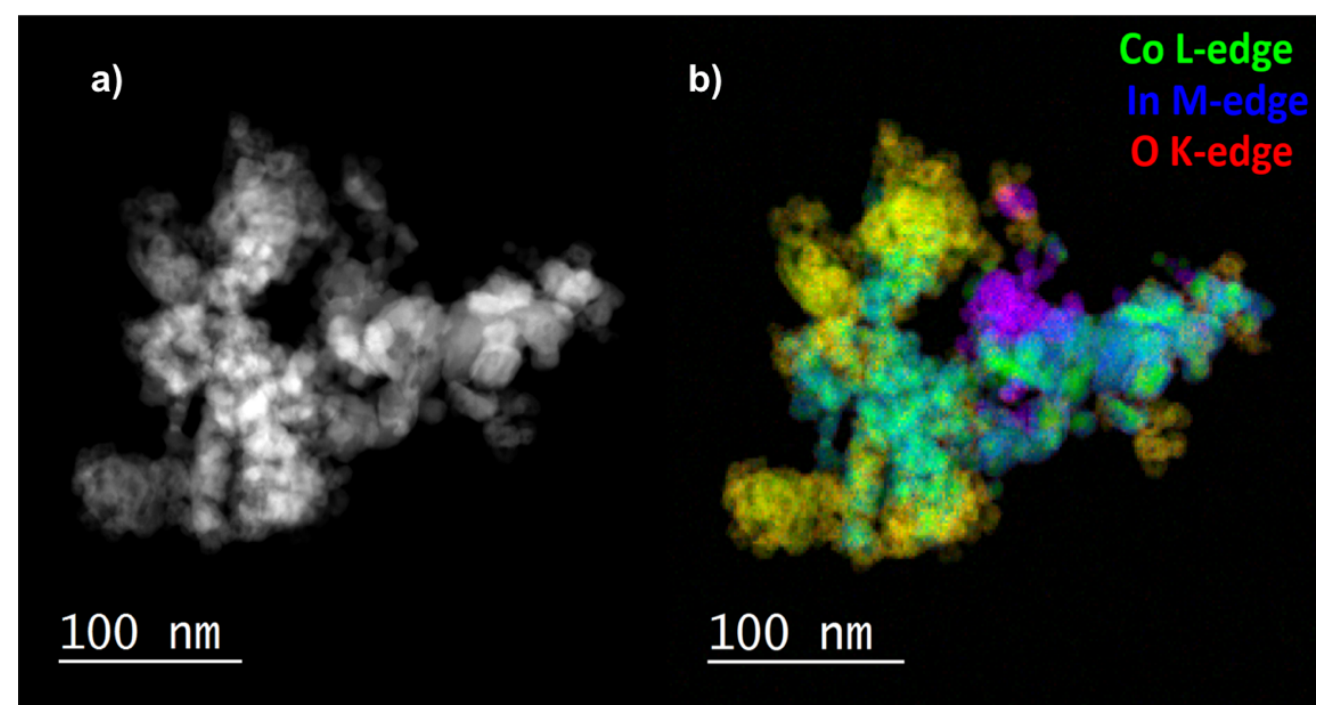

Figure 3 Low magnification ADF-STEM imaging and elemental mapping of the In@Co-1 catalyst after the reaction: (a) dark field imaging, b) colour mix built with elemental maps computed from EELS data: Co (green), In (blue) and $O$ (red).

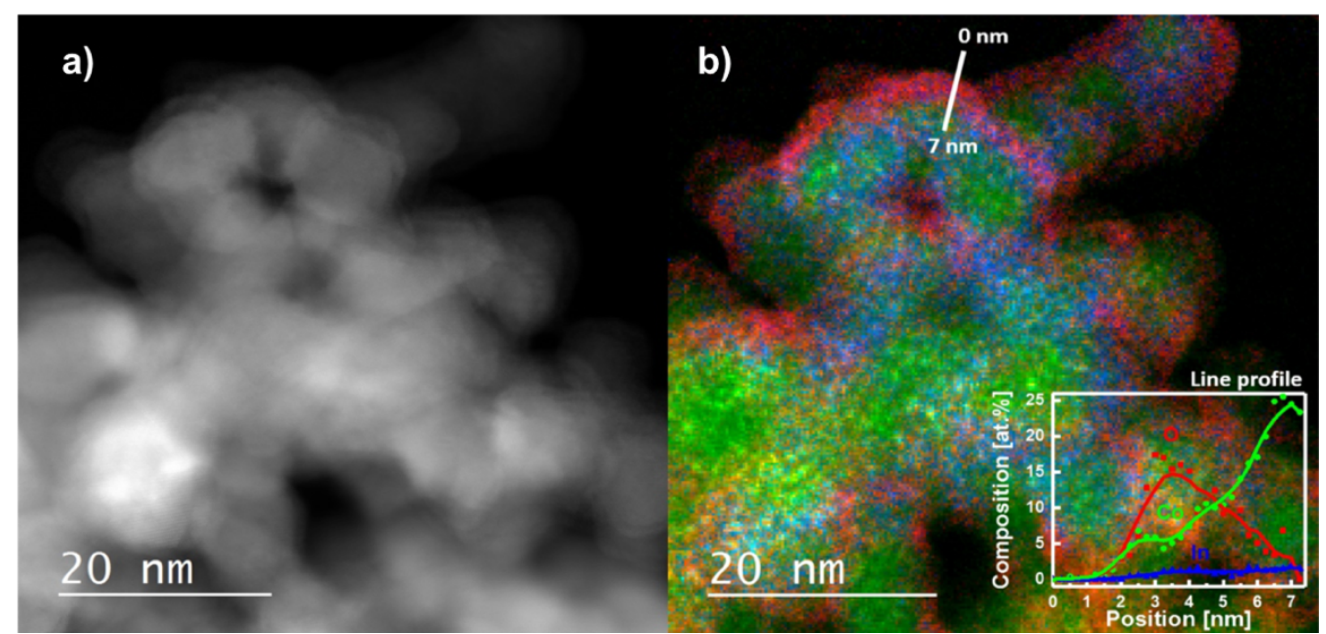

Figure 4 ADF-STEM imaging and elemental mapping of metallic Co nanoparticles covered by an indium layer after the reaction: (a) dark field imaging, b) colour mix built with quantitative elemental maps computed from EELS data: Co (green), In (blue) and $O$ (red). The inset shows a line profile of the Co, $O$ and In atomic composition from the surface to the bulk (carbon edge taken into account during quantitative analysis).

Surface characterization by XPS suggests that the surface state is also heavily modified after the reaction. The elemental composition (Figure S7) evolves with a 
decrease in the oxygen content from 49.9 at.\% to 20.5 at.\% and a simultaneous increase in the carbon content from 13.2 at.\% to 24.6 at.\%. This result is consistent with the formation of the mixed ColnC $\mathrm{C}_{0.75}$ carbide and the remaining presence of $\ln _{2} \mathrm{O}_{3}$. The Co/In ratio decreases markedly from 6.5 to 2 . Overall, this result means that the In@Co solids rearranged during $\mathrm{CO}_{2}$ hydrogenation to present more indium on their surface, which is also in accordance with the TEM results (vide supra). Figure za shows the high-resolution XPS spectrum of the Co $2 p$ core level of the sample after the reaction. The Co $2 p_{3 / 2}$ is well fitted using a combination of the parameters derived from metallic cobalt and mixed cobalt oxides from standard samples. The dominant Co $2 p_{3 / 2}$ is located at $778.2 \mathrm{eV}$ and corresponds to metallic cobalt and/or cobalt carbides, whereas the broad peak centred at approximately $\sim 781.1 \mathrm{eV}$ corresponds to cobalt mixed oxides. $26,33,34$ The In@Co catalyst still contains $7.1 \%$ oxidized cobalt atoms after the reaction. The $\ln 3 \mathrm{~d}_{5 / 2}$ peak was fitted using two components located at 443.7 $\mathrm{eV}$ and $444.7 \mathrm{eV}$ attributed to indium in a metallic state or within the ColnC $\mathrm{C}_{0.75}$ carbide (55.7 at.\%) ${ }^{35}$ and to indium in $\ln _{2} \mathrm{O}_{3}\left(44.3\right.$ at.\%). ${ }^{35,36}$

It is very difficult to distinguish between the metallic and carbide states considering only the Co $2 p$ and In $3 d$ core levels since they have similar binding energies. To substantiate the presence of the metallic carbide using XPS, a highresolution spectrum at the $\mathrm{C}_{1 \mathrm{~s}}$ core level of the sample after the reaction was recorded (Figure 2c). The $\mathrm{C}_{1 \mathrm{~s}}$ core level from the sample after the reaction was fitted using seven components located at $283.4 \mathrm{eV}, 284.4 \mathrm{eV}, 285.0 \mathrm{eV}, 285.7 \mathrm{eV} 286.7 \mathrm{eV}, 288.2 \mathrm{eV}$ and $289.6 \mathrm{eV}$ corresponding to $\mathrm{C}-\mathrm{Co}^{33,34,37}, \mathrm{C}=\mathrm{C}(s p 2)^{37}, \mathrm{C}-\mathrm{C} / \mathrm{C}-\mathrm{H}(s p 3)^{29}, \mathrm{CO}-\mathrm{Co}^{37,38}$, $\mathrm{C}-\mathrm{O}, \mathrm{C}=\mathrm{O}$ and $\mathrm{O}-\mathrm{C}=\mathrm{O}$ bonds. ${ }^{28,29}$ In comparison to the In@Co precatalyst, the appearance of Coln $\mathrm{C}_{0.75}$ carbide and the presence of both graphitic carbon and $\mathrm{CO}$ adsorbed on metallic cobalt were observed for the In@Co catalyst after the reaction.

Unravelling the active catalytic phase. With the composition of the In@Co-1 catalyst in hand, catalytic tests were performed with individual components and their physical mixtures (Table S4). Cobalt oxide, once converted to metallic Co under the reaction conditions, predictably converted carbon dioxide to methane with $100 \%$ selectivity. Pure $\operatorname{In}_{2} \mathrm{O}_{3}$ showed a negligible conversion of approximately $1 \%$ with carbon monoxide as the only product. $\mathrm{A} 97 \%$ pure $\mathrm{Co}_{3} \mathrm{InCoC} \mathrm{C}_{0.75}$ phase was obtained from metal organic framework-mediated synthesis via pyrolysis of a Co-In MOF (see the SI). The resultant $\mathrm{Co}_{3} \mathrm{InC}_{0.75}$ carbide, alone or mixed with $\ln _{2} \mathrm{O}_{3}$ in different proportions, did not produce any methanol, but did produce $\mathrm{CO}$. The systematic elimination of the former candidates suggests that the oxidized indium-cobalt layer around metallic cobalt is the active phase for the selective formation of methanol. Indeed, there are precedents in the literature where $\mathrm{Ni}, \mathrm{Co}, \mathrm{Cu}$ metal nanoparticles were alloyed with indium and tested for the selective hydrogenation of carboxylic acids to alcohols. When compared against the parent monometallic catalyst, a systematic suppression of the hydro-decarbonylation reaction was found. ${ }^{39-41}$ By analogy, we propose that indium poisons the surface of metallic cobalt, hindering its total hydrogenation activity (approximately $80 \% \mathrm{CO}_{2}$ conversion on metallic Co vs. $19 \%$ on In@Co-1). This surface modification may also prevent methane formation due to a 
slower hydrogenolysis rate of the $\mathrm{C}-\mathrm{O}$ bond compared to the desorption rate of the $\mathrm{CO}$ and $\mathrm{CH}_{3} \mathrm{OH}$ intermediates. The influence of the In content on the catalytic performance also supports this hypothesis. Figure 5 shows the catalytic behaviour of catalysts that were prepared by the same method at varying the indium and cobalt contents. The best performance is achieved on catalysts with an In/Co ratio of 0.38 . Decreasing the indium content in the solid leads to a higher yield of undesired methane; in this case, the surface of metallic cobalt is less perturbed by the presence of indium and thus can eventually achieve the complete hydrogenation of carbon dioxide. In contrast, with a high indium content, the selectivity towards methane drops to $1 \%$, together with a drastic decrease in the conversion rate (19\% vs. $11 \%)$.

a)

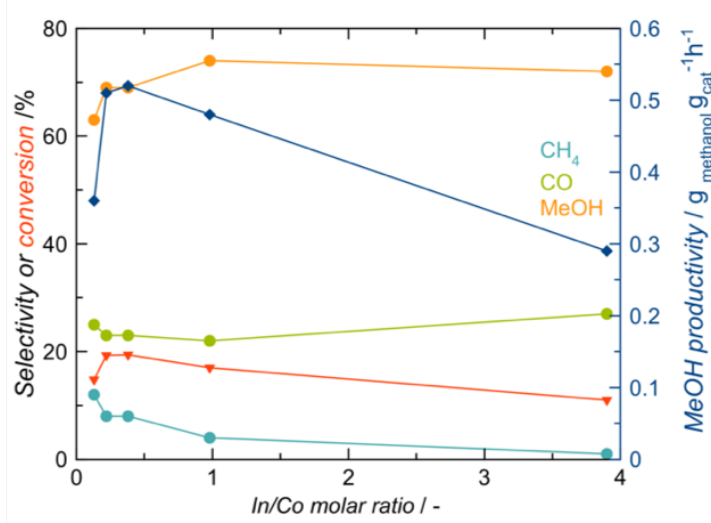

b)

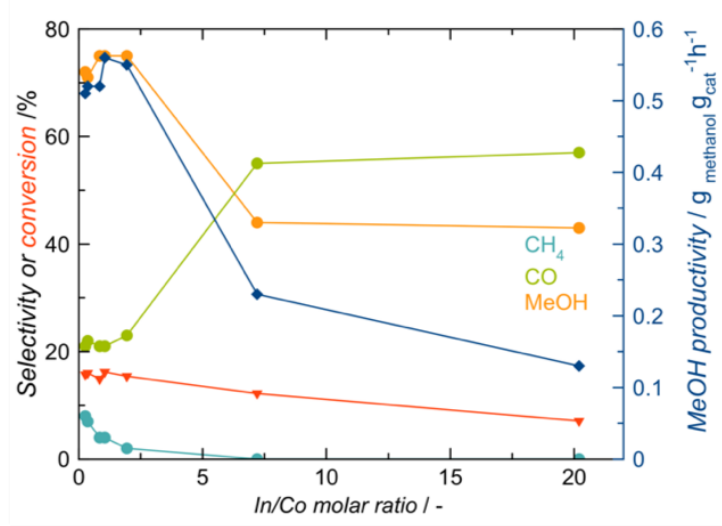

Figure 5. Catalytic activity of a) In@Co-1 and b) In@Co-2 catalysts with different indium to cobalt ratios.

Optimization of the catalyst formulation. Despite its promising performances, the first In@Co-1 catalyst has substantial heterogeneity due to significant amounts of $\ln _{2} \mathrm{O}_{3}$ and $\mathrm{Co}_{3} \mathrm{O}_{4}$ phases that do not contribute to the selective formation of methanol. We hypothesized that the heterogeneity after the induction period arises mainly from the initial heterogeneity in the precatalyst. Achieving better mixing of indium and cobalt in the as-synthesized solid is expected to enhance the formation of the relevant active phase. To this end, the hydrothermal treatment used for the previous preparation of In@Co-1 samples was omitted to avoid segregation of the $\ln (\mathrm{OH})_{3}$ and $\mathrm{Co}_{3} \mathrm{O}_{4}$ phases. Hence, a second series of catalysts with varying $\mathrm{In} / \mathrm{Co}$ ratios was prepared and denoted as In@Co-2.

The In@Co-2 precatalyst is composed of an intricate mixture of Co and In atoms with some crystalline and amorphous components, as observed by ADFSTEM/EELS (Figure S6). The crystalline part was characterized by PXRD as a mixture of $\mathrm{CoO}$ and $\mathrm{In}_{2} \mathrm{O}_{3}$ nanoparticles (Figure S9). In addition, the nitrogen adsorptiondesorption isotherms of materials synthesized without hydrothermal treatment are type IV, which is typical of a mesoporous solid (Figure S3 b). The specific surface area markedly increased to a range of $80-200 \mathrm{~m}^{2} \mathrm{~g}^{-1}$ compared to the initial $30 \mathrm{~m}^{2} \mathrm{~g}^{-1}$ of the In@Co-1 precatalyst. The crystalline phases after catalyst activation were also found to be a mixture of $\mathrm{Co}_{3} \operatorname{lnC}_{0.75}, \operatorname{In}_{2} \mathrm{O}_{3}$ and $\mathrm{Co}(f c c)$ phases similar to the In@Co-1 catalyst (Figure S9) 
When applied in $\mathrm{CO}_{2}$ hydrogenation, a similar effect of indium loading on the catalytic performance was observed (Figure 5). However, in this case, due to the better initial dispersion of In, a broader range for the optimum molar ratio of $\mathrm{In} / \mathrm{Co}$ was found. At the same time, both higher productivities and selectivities were observed. A catalytic run with the In@Co-2 catalyst $(\mathrm{In} / \mathrm{Co}=1)$ was performed for $170 \mathrm{~h}$ starting under the same chosen standard conditions of $300^{\circ} \mathrm{C}$ and 50 bar (Figure 6). The results show the same induction period of $30 \mathrm{~h}$ followed by a stable performance, reaching a $\mathrm{CO}_{2}$ conversion of $16 \%$. The selectivity of methanol reached $75 \%$, with a limited formation of carbon monoxide $\left(\mathrm{S}_{\mathrm{CO}}=21 \%\right)$ and methane $\left(\mathrm{S}_{\mathrm{CH} 4}=4 \%\right)$. Increasing the gas hourly space velocity (GHSV) from $14400 \mathrm{~h}^{-1}$ to $22200 \mathrm{~h}^{-1}$, the selectivity towards methanol reached $79 \%$ with a decrease in the selectivity towards methane from 4 to $2 \%$ at a methanol productivity of $0.76 \mathrm{gmeOH}_{\mathrm{gcat}}{ }^{-1} \mathrm{~h}^{-1}$. Further increasing the GHSV to $27500 \mathrm{~h}^{-1}$ leads to a record methanol productivity of $0.86 \mathrm{gmeOH}_{\mathrm{cat}}{ }^{-1} \mathrm{~h}^{-1}$ at a slighty increased selectivity to methanol of $81 \%$. Decreasing the temperature to $285{ }^{\circ} \mathrm{C}$ results in selectivities to methanol on the order of $85 \%$ with a negligible formation of undesired methane.

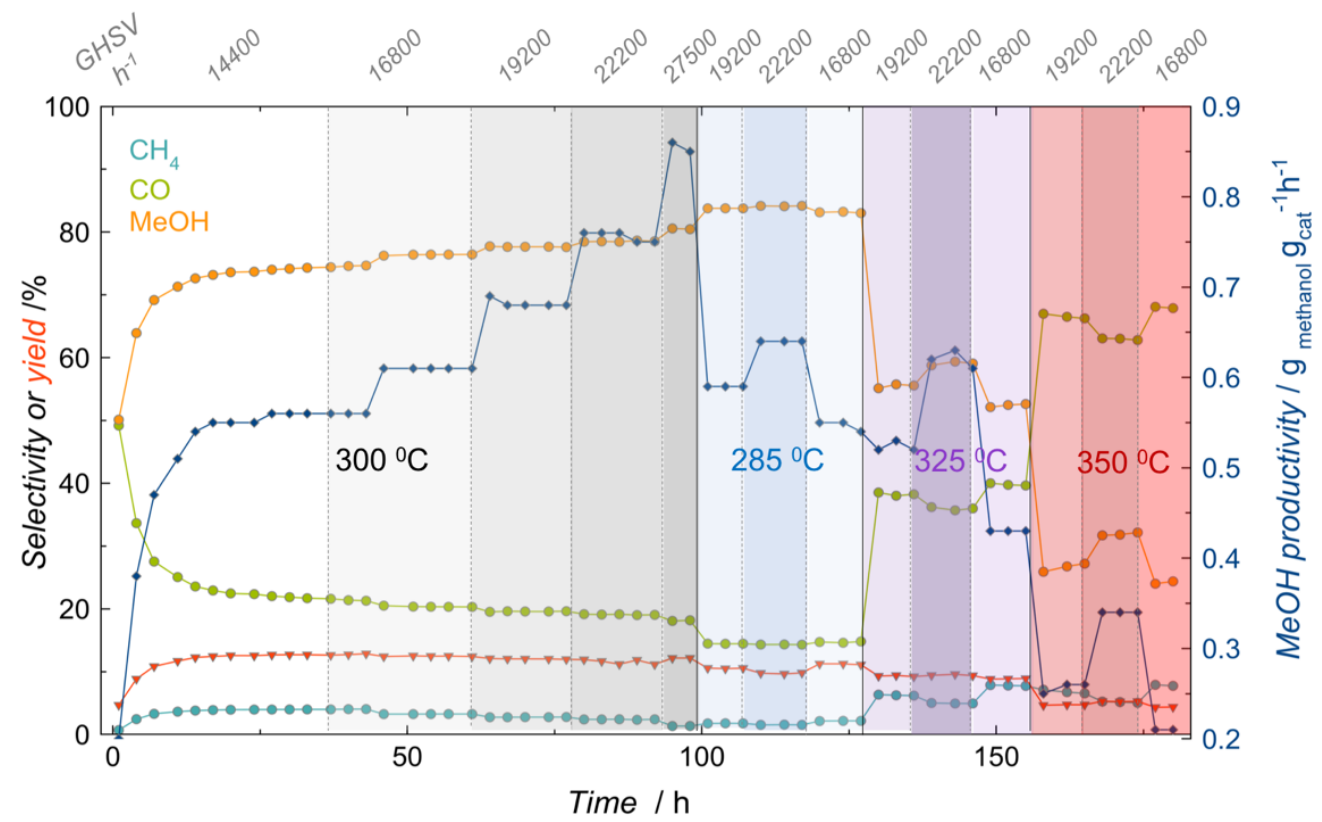

Figure 6. Methanol selectivity, yield and productivity over an In@Co-2 catalyst at different temperatures and feed flows. Reaction conditions (unless otherwise stated in the figure itself) are $300{ }^{\circ} \mathrm{C}, 50 \mathrm{bar}, 80 \% \mathrm{H}_{2}$ $20 \% \mathrm{CO}_{2}$ feed, $50 \mathrm{mg}$ of catalyst, $56.1 \mathrm{wt} \%$ In in the precatalyst. 


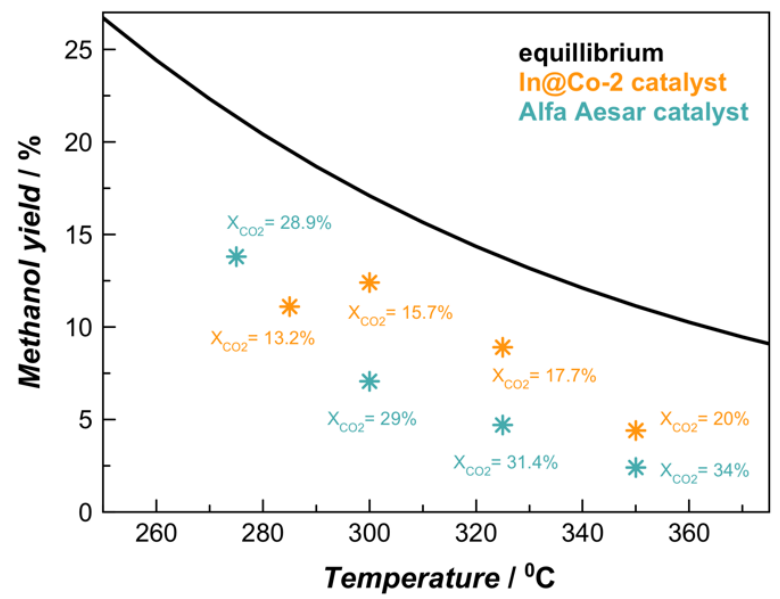

Figure 7. Comparison of the In@Co-2 system to the conventional Cu-based catalyst from Alfa Aesar. Reaction conditions: 50 bar, $80 \% \mathrm{H}_{2} 20 \% \mathrm{CO}_{2}$ feed, 50 mg of In@Co-2 catalyst, 56.1 wt $\%$ In in the precatalyst.

To extend the comparison between In@Co-2 and $\mathrm{Cu}-\mathrm{ZnO}-\mathrm{Al}_{2} \mathrm{O}_{3}$, for experiments performed under exactly the same conditions, the $\mathrm{MeOH}$ yield at 50 bar is plotted for temperatures ranging from $250{ }^{\circ} \mathrm{C}$ to $350{ }^{\circ} \mathrm{C}$ against thermodynamic equilibrium conversion (Figure 7). From this figure, it is clear that the In@Co-2 system can maintain high methanol selectivities over a wider range of temperatures than the commercial $\mathrm{Cu}-\mathrm{ZnO}-\mathrm{Al}_{2} \mathrm{O}_{3}$, allowing a much higher productivity per pass. Even when compared with more recent developments $\left(\mathrm{ZnO}-\mathrm{ZrO}_{2},{ }^{22}\right.$ vide supra), both in terms of yield per pass and productivity, the reported In@Co catalyst in this study establishes itself as a new state-of-the-art catalyst.

\section{Conclusions}

We reported a novel indium/cobalt-based system for the production of methanol from carbon dioxide. Indium, when in close proximity to $\mathrm{Co}$, is able to tune its selectivity from methane formation to methanol formation while maintaining a highly productive catalyst, even under conditions close to thermodynamic control. The reported catalysts are easy to prepare and show outstanding stability under relevant process conditions. Our results, in addition to establishing a new state-of-the-art system for this important transformation, highlight the importance of metal doping and may have important implications for other fields of catalysis, such as electrocatalysis.

\section{METHODS}

\section{Catalyst preparation}

The starting materials were cobalt acetate $\left(\mathrm{Co}\left(\mathrm{CH}_{3} \mathrm{COO}\right)_{2} \cdot 6 \mathrm{H}_{2} \mathrm{O}\right)$, indium acetate $\left(\mathrm{In}\left(\mathrm{CH}_{3} \mathrm{COO}\right)_{3}\right)$, water, hydrogen peroxide and ammonia hydroxide solution. Both salts were dissolved in water and added dropwise to a stirred aqueous solution of $\mathrm{H}_{2} \mathrm{O}_{2}$ and $\mathrm{NH}_{4} \mathrm{OH}$. The mixture further underwent hydrothermal treatment at $180{ }^{\circ} \mathrm{C}$ for $8 \mathrm{~h}$. The obtained powder, denoted as In@Co, was recovered, washed and subsequently dried at $60{ }^{\circ} \mathrm{C}$. The compositional, textural, and structural properties of the In@Co catalyst were investigated by 
powder X-ray diffraction, high-resolution transmission electron microscopy, electron energy loss spectroscopy, temperature-programmed reduction with $\mathrm{H}_{2}$, and X-ray photoelectron spectroscopy. $\mathrm{CO}_{2}$ hydrogenation was performed over undiluted catalysts using a Flowrence $\circledR$ 16 parallel reactor system. Prior to the reaction, the In@Co catalyst was preheated in $\mathrm{N}_{2}$ at $300{ }^{\circ} \mathrm{C}$ and 1 bar for $1 \mathrm{~h}$. Further details on catalyst preparation, characterization, and tests are given in the Supporting Information.

1 Geden, O. Politically informed advice for climate action. Nature Geoscience 11, 380383, doi:10.1038/s41561-018-0143-3 (2018).

2 Olah George, A. Beyond Oil and Gas: The Methanol Economy. Angewandte Chemie International Edition 44, 2636-2639, doi:10.1002/anie.200462121 (2005).

3 Álvarez, A. et al. Challenges in the Greener Production of Formates/Formic Acid, Methanol, and DME by Heterogeneously Catalyzed CO2 Hydrogenation Processes. Chemical Reviews 117, 9804-9838, doi:10.1021/acs.chemrev.6b00816 (2017).

4 Turner, J. et al. Renewable hydrogen production. International Journal of Energy Research 32, 379-407, doi:10.1002/er.1372 (2007).

5 Wu, J., Huang, Y., Ye, W. \& Li, Y. CO2 Reduction: From the Electrochemical to Photochemical Approach. Advanced Science 4, 1700194, doi:10.1002/advs.201700194 (2017).

6 Wang, L. et al. Photocatalytic Hydrogenation of Carbon Dioxide with High Selectivity to Methanol at Atmospheric Pressure. Joule, doi:10.1016/j.joule.2018.03.007.

7 Wang, W.-H., Himeda, Y., Muckerman, J. T., Manbeck, G. F. \& Fujita, E. CO2 Hydrogenation to Formate and Methanol as an Alternative to Photo- and Electrochemical CO2 Reduction. Chemical Reviews 115, 12936-12973, doi:10.1021/acs.chemrev.5b00197 (2015).

8 Kar, S., Kothandaraman, J., Goeppert, A. \& Prakash, G. K. S. Advances in catalytic homogeneous hydrogenation of carbon dioxide to methanol. Journal of CO2 Utilization 23, 212-218, doi:https://doi.org/10.1016/j.jcou.2017.10.023 (2018).

9 Ribeiro, A. P. C., Martins, L. M. D. R. S. \& Pombeiro, A. J. L. Carbon dioxide-tomethanol single-pot conversion using a C-scorpionate iron(ii) catalyst. Green Chemistry 19, 4811-4815, doi:10.1039/C7GC01993A (2017).

10 Schneidewind, J., Adam, R., Baumann, W., Jackstell, R. \& Beller, M. LowTemperature Hydrogenation of Carbon Dioxide to Methanol with a Homogeneous Cobalt Catalyst. Angewandte Chemie International Edition 56, 1890-1893, doi:10.1002/anie.201609077 (2017).

11 Wesselbaum, S., vom Stein, T., Klankermayer, J. \& Leitner, W. Hydrogenation of Carbon Dioxide to Methanol by Using a Homogeneous Ruthenium-Phosphine Catalyst. Angewandte Chemie International Edition 51, 7499-7502, doi:10.1002/anie.201202320 (2012).

12 Tominaga, K.-i., Sasaki, Y., Watanabe, T. \& Saito, M. Homogeneous Hydrogenation of Carbon Dioxide to Methanol Catalyzed by Ruthenium Cluster Anions in the Presence of Halide Anions. Bulletin of the Chemical Society of Japan 68, 2837-2842, doi:10.1246/bcsj.68.2837 (1995).

13 Kothandaraman, J., Goeppert, A., Czaun, M., Olah, G. A. \& Prakash, G. K. S. Conversion of $\mathrm{CO} 2$ from Air into Methanol Using a Polyamine and a Homogeneous Ruthenium Catalyst. Journal of the American Chemical Society 138, 778-781, doi:10.1021/jacs.5b12354 (2016). 
14 Wesselbaum, S. et al. Hydrogenation of carbon dioxide to methanol using a homogeneous ruthenium-Triphos catalyst: from mechanistic investigations to multiphase catalysis. Chemical Science 6, 693-704, doi:10.1039/C4SC02087A (2015).

15 Pérez-Fortes, M., Schöneberger, J. C., Boulamanti, A. \& Tzimas, E. Methanol synthesis using captured $\mathrm{CO} 2$ as raw material: Techno-economic and environmental assessment. Applied Energy 161, 718-732, doi:https://doi.org/10.1016/j.apenergy.2015.07.067 (2016).

16 Collins, S. E. et al. The role of $\mathrm{Pd}-\mathrm{Ga}$ bimetallic particles in the bifunctional mechanism of selective methanol synthesis via $\mathrm{CO} 2$ hydrogenation on a $\mathrm{Pd} / \mathrm{Ga} 2 \mathrm{O} 3$ catalyst. Journal of Catalysis 292, 90-98, doi:https://doi.org/10.1016/j.jcat.2012.05.005 (2012).

17 Fujitani, T. et al. Development of an active Ga2O3 supported palladium catalyst for the synthesis of methanol from carbon dioxide and hydrogen. Applied Catalysis A: General 125, L199-L202, doi:https://doi.org/10.1016/0926-860X(95)00049-6 (1995).

18 Chiavassa, D. L., Collins, S. E., Bonivardi, A. L. \& Baltanás, M. A. Methanol synthesis from $\mathrm{CO} 2 / \mathrm{H} 2$ using $\mathrm{Ga} 2 \mathrm{O} 3-\mathrm{Pd} /$ silica catalysts: Kinetic modeling. Chemical Engineering Journal 150, 204-212, doi:https://doi.org/10.1016/j.cej.2009.02.013 (2009).

19 Hartadi, Y., Widmann, D. \& Behm, R. J. Methanol synthesis via CO2 hydrogenation over a $\mathrm{Au} / \mathrm{ZnO}$ catalyst: an isotope labelling study on the role of $\mathrm{CO}$ in the reaction process. Physical Chemistry Chemical Physics 18, 10781-10791, doi:10.1039/C5CP06888F (2016).

20 Studt, F. et al. Discovery of a Ni-Ga catalyst for carbon dioxide reduction to methanol. Nature Chemistry 6, 320, doi:10.1038/nchem.1873

https://www.nature.com/articles/nchem.1873\#supplementary-information (2014).

21 Martin, O. et al. Indium Oxide as a Superior Catalyst for Methanol Synthesis by CO2 Hydrogenation. Angewandte Chemie International Edition 55, 6261-6265, doi:10.1002/anie.201600943 (2016).

22 Wang, J. et al. A highly selective and stable ZnO-ZrO\&lt;sub\&gt;2\&lt;/sub\&gt; solid solution catalyst for CO\&lt;sub\&gt;2\&lt;/sub\&gt; hydrogenation to methanol. Science Advances 3 (2017).

$23 \mathrm{Li}, \mathrm{C}$.-S. et al. High-performance hybrid oxide catalyst of manganese and cobalt for low-pressure methanol synthesis. Nature Communications 6, 6538, doi: $10.1038 /$ ncomms 7538

https://www.nature.com/articles/ncomms7538\#supplementary-information (2015).

24 Li, D., Liu, X., Zhang, Q., Wang, Y. \& Wan, H. Cobalt and Copper Composite Oxides as Efficient Catalysts for Preferential Oxidation of CO in H2-Rich Stream. Catalysis Letters 127, 377-385, doi:10.1007/s10562-008-9693-0 (2009).

25 Younis, A., Chu, D., Lin, X., Lee, J. \& Li, S. Bipolar resistive switching in p-type Co3O4 nanosheets prepared by electrochemical deposition. Nanoscale Research Letters 8, 36, doi:10.1186/1556-276X-8-36 (2013).

26 Biesinger, M. C. et al. Resolving surface chemical states in XPS analysis of first row transition metals, oxides and hydroxides: $\mathrm{Cr}, \mathrm{Mn}, \mathrm{Fe}, \mathrm{Co}$ and Ni. Applied Surface Science 257, 2717-2730, doi:https://doi.org/10.1016/j.apsusc.2010.10.051 (2011).

27 Detweiler, Z. M., Wulfsberg, S. M., Frith, M. G., Bocarsly, A. B. \& Bernasek, S. L. The oxidation and surface speciation of indium and indium oxides exposed to atmospheric oxidants. Surface Science $\mathbf{6 4 8}, \quad$ 188-195, doi:https://doi.org/10.1016/j.susc.2015.10.026 (2016). 
28 Zhang, L., Chen, G., Hedhili, M. N., Zhang, H. \& Wang, P. Three-dimensional assemblies of graphene prepared by a novel chemical reduction-induced self-assembly method. Nanoscale 4, 7038-7045, doi:10.1039/C2NR32157B (2012).

29 Desimoni, E. \& Brunetti, B. X-Ray Photoelectron Spectroscopic Characterization of Chemically Modified Electrodes Used as Chemical Sensors and Biosensors: A Review. Chemosensors 3, doi:10.3390/chemosensors3020070 (2015).

30 Koga, N. \& Kimizu, T. Thermal Decomposition of Indium(III) Hydroxide Prepared by the Microwave-Assisted Hydrothermal Method. Journal of the American Ceramic Society 91, 4052-4058, doi:10.1111/j.1551-2916.2008.02811.x (2008).

31 Stadelmaier, H. H. \& Manaktala, H. K. Intermetallic CoIn2, a representative of the CuMg2 structure type. Acta Crystallographica Section B 31, 374-378, doi:10.1107/S056774087500283X (1975).

32 Pöttgen, R., Hoffmann, R.-D. \& Kotzyba, G. Structure, Chemical Bonding and Properties of CoIn3, RhIn3, and IrIn3. Zeitschrift für anorganische und allgemeine Chemie 624, 244-250, doi:10.1002/(SICI)1521-3749(199802)624:2<244::AIDZAAC244>3.0.CO;2-G (1999).

33 Zhang, T. et al. Cobalt and cobalt carbide on alumina/NiAl(110) as model catalysts. Catalysis Science \& Technology 7, 5893-5899, doi:10.1039/C7CY01806A (2017).

34 Kong, A., Lin, Q., Mao, C., Bu, X. \& Feng, P. Efficient oxygen reduction by nanocomposites of heterometallic carbide and nitrogen-enriched carbon derived from the cobalt-encapsulated indium-MOF. Chemical Communications 50, 15619-15622, doi:10.1039/C4CC06867J (2014).

35 Lin, A. W. C., Armstrong, N. R. \& Kuwana, T. X-ray photoelectron/Auger electron spectroscopic studies of tin and indium metal foils and oxides. Analytical Chemistry 49, 1228-1235, doi:10.1021/ac50016a042 (1977).

36 Jo, G. et al. Structural and electrical characterization of intrinsic n-type In2O3 nanowires. Colloids and Surfaces A: Physicochemical and Engineering Aspects 313314, 308-311, doi:https://doi.org/10.1016/j.colsurfa.2007.04.166 (2008).

37 Liu, Q. et al. CO2 Activation on Cobalt Surface in the Presence of H2O: An AmbientPressure X-ray Photoelectron Spectroscopy Study. Catalysis Letters 148, 1686-1691, doi:10.1007/s10562-018-2362-z (2018).

$38 \mathrm{Wu}$, C. H., Eren, B., Bluhm, H. \& Salmeron, M. B. Ambient-Pressure X-ray Photoelectron Spectroscopy Study of Cobalt Foil Model Catalyst under CO, H2, and Their Mixtures. ACS Catalysis 7, 1150-1157, doi:10.1021/acscatal.6b02835 (2017).

39 Onyestyák, G. Non-precious Metal Catalysts for Acetic Acid Reduction. Periodica Polytechnica Chemical Engineering 61, 270-277 (2017).

40 Onyestyák, G. et al. in Open Chemistry Vol. 13 (2014).

41 Onyestyák, G., Harnos, S. \& Kalló, D. Bioacid Hydroconversion over Co, Ni, Cu Mono- and Indium-doped Bimetallic Catalysts. Acta Chimica Slovenica; Vol 62, No 1 (2015), doi:10.17344/acsi.2014.1135 (2015). 